\title{
Comparative Evaluation of Depth of Cure between Two Bulk-fill Composites and a Conventional Resin Composite: An In Vitro Study
}

\author{
Meera Bastian ${ }^{1}$, RV Vineet $^{2}$, Josey Mathew ${ }^{3}$, Liza George $^{4}$, Sinju Paul ${ }^{5}$, Tom P Varghese ${ }^{6}$
}

\begin{abstract}
Aim and objective: To evaluate and compare the depth of cure of two bulk-fill composites with a conventional composite.

Materials and methods: A sample size of 36 was taken and divided into three groups based on the type of composite. Standardized cylindrical stainless steel molds were prepared with $8 \mathrm{~mm}$ diameter and $10 \mathrm{~mm}$ depth. Measurement of depth of cure by the scraping method was performed according to the ISO 4049 (2009). After placing the specimens, the mold was pressed with polyester strips covered by glass slides and curing was initiated using Bluephase 20i (Ivoclar Vivadent US) light-curing unit through the glass slide. Immediately after curing, the specimens were removed from the mold and the uncured part of the specimens was removed by scraping with a plastic spatula. The absolute length of the hardened composite specimen was measured using a digital vernier caliper. The measured length was divided by two and recorded as the ISO depth of cure.

Results: The depth of cure of the composite specimens was found to be higher for Voco Xtra Fil bulk-fill composite than for Shofu Beautifil bulk-fill composite and Filtek Z350 XT conventional composite (3M/ESPE).

Conclusion: Within the limitations of the study, it can be concluded that the placement of bulk-fill composites with 3-mm increments is mandatory for complete curing.

Clinical significance: Depth of cure of bulk-fill composites determines the adaptation of restoration to the tooth structure, and this study aims to evaluate two newly introduced bulk-fill composites using scrape test.
\end{abstract}

Keywords: Bulk-fill composites, Conventional composite, Depth of cure, Polymerization shrinkage.

Conservative Dentistry and Endodontic Journal (2020): 10.5005/jp-journals-10048-0063

\section{INTRODUCTION}

Dental composites are the most widely used direct tooth-colored esthetic restorative materials. For many decades, composite resin restorations were considered as a suitable restorative choice for anterior teeth. ${ }^{1}$ However, current advances in their mechanical properties along with advancements in adhesive systems have broadened their application in posterior restorations. ${ }^{2}$ The conventional methods of composite restoration are, however, time-consuming and technically challenging as they require incremental filling technique for complete polymerization of the material. Time-saving restorative materials are an ongoing demand for posterior applications. Hence, bulk-fill resin composites (BFRCs) have been introduced in the market to improve the efficiency of restorative procedures. ${ }^{3}$

The depth of cure is defined as the thickness of a resin that may be converted from a monomer to polymer at a specific light-curing condition. ${ }^{4}$ Studies have reported that bulk-fill composites can be filled and cured up to 4-mm thickness in a single increment without affecting polymerization shrinkage, degree of conversion, and cavity adaptation. ${ }^{5}$ When composite resin is cured in a single bulk layer, there may be a reduction in the degree of polymerization at the deeper portion due to the attenuation of the light. Uncured composite resins at the base of the restoration may cause polymerization shrinkage, secondary caries, pulpal irritation, and postoperative sensitivity. ${ }^{6}$ Therefore, the depth of cure during the placement is a major issue faced by bulk-fill composite resins. There are only limited studies investigating the depth of cure of bulk-fill composites. The purpose
${ }^{1-6}$ Department of Conservative Dentistry and Endodontics, Annoor Dental College and Hospital, Muvattupuzha, Kerala, India

Corresponding Author: Meera Bastian, Department of Conservative Dentistry and Endodontics, Annoor Dental College and Hospital, Muvattupuzha, Kerala, India, Phone: +91 8277385874, e-mail: drmeerabastian@gmail.com

How to cite this article: Bastian M, Vineet RV, Mathew J, et al. Comparative Evaluation of Depth of Cure between Two Bulk-fill Composites and a Conventional Resin Composite: An In Vitro Study. Cons Dent Endod J 2020;5(2):23-27.

Source of support: Nil

Conflict of interest: None

of this study was to evaluate the depth of cure of two bulk-fill composites and compare it with a conventional composite.

\section{Aim and Objective}

To evaluate and compare the depth of cure of two bulk-fill composites with a conventional composite.

\section{Sample Size Estimation}

Sample size is estimated using the formula

$$
n=\frac{\left(Z_{1-\alpha / 2}+Z_{1-\beta}\right)^{2} \times \sigma^{2}}{d^{2}}
$$


where $Z_{1-\alpha / 2}$ is the value of $Z$ at significance level $5 \%, Z_{1-\beta}$ is the value of $Z$ at power $95 \%, \sigma$ is the standard deviation of the population, and $d$ is the difference between the means.

The effect size is 0.7.

Actual power $=0.9574$.

A sample size of 12 per group was calculated using the above formula.

\section{Materials and Methods}

Standardized cylindrical stainless steel molds were prepared with $8 \mathrm{~mm}$ diameter and $10 \mathrm{~mm}$ depth. A sample size of 36 was taken and divided into three groups based on the type of composite (Table 1).

Measurement of depth of cure by the scraping method was performed according to the ISO 4049 (2009) (International Organization for Standardization for polymer-based restorative materials). ${ }^{6}$ Vaseline was applied to the mold for the easy removal of composite resin from the mold. After placing the specimens (Fig. 1), the mold was pressed with polyester strips covered by glass slides and curing was initiated using Bluephase 20i (Ivoclar Vivadent US) light-curing unit (light intensity up to $2,000 \mathrm{~mW} / \mathrm{cm}^{2}$ ) through the glass slide (Fig. 2). Immediately after curing, the specimens were removed from the mold and the uncured part of the specimens was removed by scraping with a plastic spatula (Fig. 3). The absolute length of the hardened composite specimen was measured using a digital vernier caliper (Figs 4 and 5). The measured length was divided by two and recorded as the ISO depth of cure.

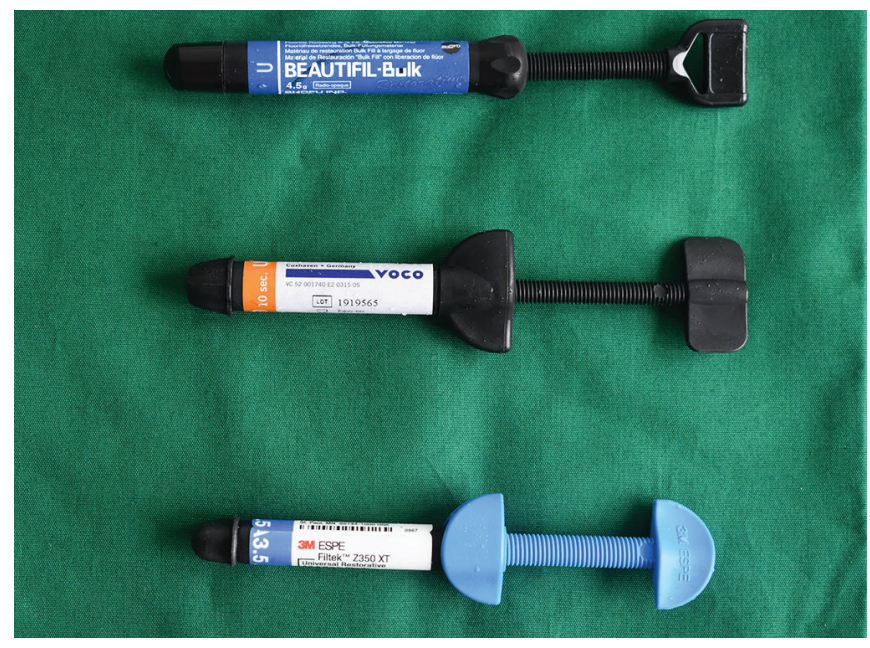

Fig. 1: Composite materials

\section{Statistical Analysis}

The ISO depth of cure of each group was analyzed by one-way ANOVA and Tukey's post hoc test using SPSS version 24.

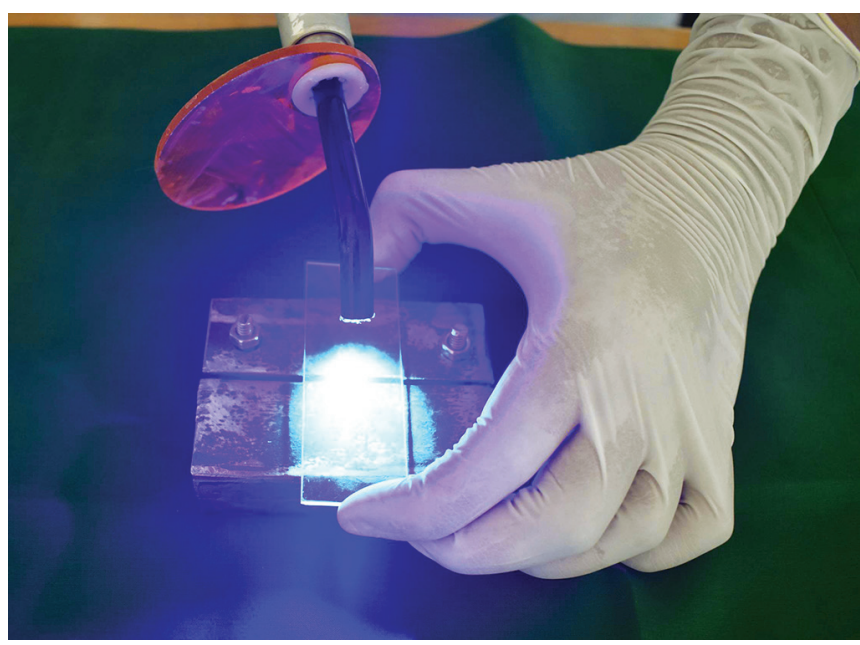

Fig. 2: Curing was initiated using Bluephase 20i (Ivoclar Vivadent) light-curing unit

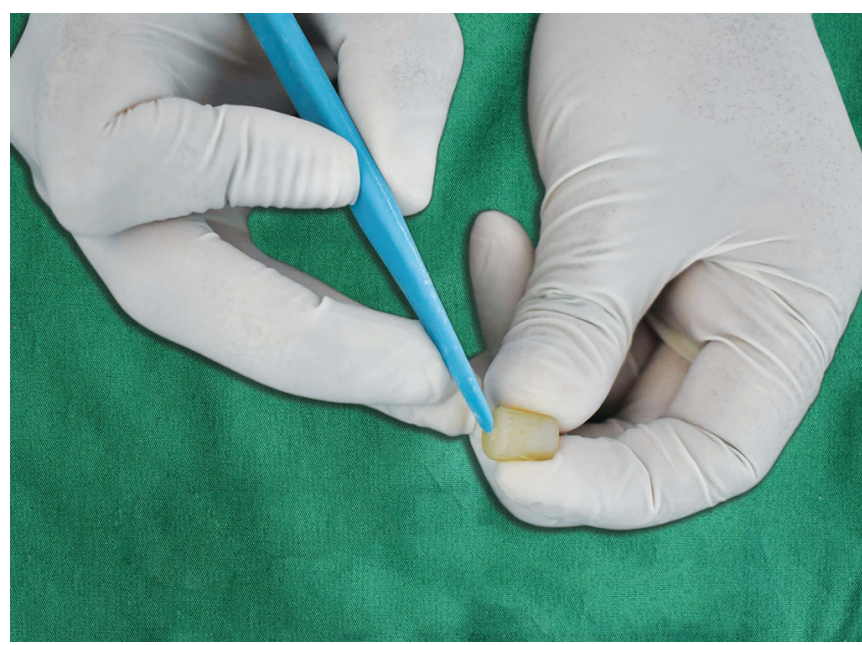

Fig. 3: Uncured part of the composite specimen

Table 1: Composite materials and their composition

\begin{tabular}{|c|c|c|c|c|c|}
\hline Composites & Matrix composition & $\begin{array}{l}\text { Filler \% by } \\
\text { weight }\end{array}$ & $\begin{array}{l}\text { Recommended } \\
\text { thickness }\end{array}$ & $\begin{array}{l}\text { Recommended curing } \\
\text { time and light intensity }\end{array}$ & $\begin{array}{l}\text { Manufacturer } \\
\text { (country) }\end{array}$ \\
\hline Beautifil bulk-fill & $\begin{array}{l}\text { Bis-GMA, UDMA, Bis-MPEPP, TEGDMA, S-PRG filler } \\
\text { based on fluoroboroaluminosilicate glass, } \\
\text { polymerization initiator, pigments, and others }\end{array}$ & 87 & $4 \mathrm{~mm}$ & $\begin{array}{l}10 \mathrm{sec} \\
\geq 1,000 \mathrm{~mW} / \mathrm{cm}^{2}\end{array}$ & $\begin{array}{l}\text { Shofu (Kyoto, } \\
\text { Japan) }\end{array}$ \\
\hline Voco Xtra Fil bulk-fill & $\begin{array}{l}\text { Inorganic filler in a methacrylate matrix (Bis-GMA, } \\
\text { UDMA, and TEGDMA) }\end{array}$ & 86 & $2 \mathrm{~mm}$ & $\begin{array}{l}10 \mathrm{sec} \\
\geq 1,000 \mathrm{~mW} / \mathrm{cm}^{2}\end{array}$ & $\begin{array}{l}\text { VOCO, GmbH, } \\
\text { Germany }\end{array}$ \\
\hline Filtek Z350 XT & $\begin{array}{l}\text { Bis-GMA, UDMA, TEGDMA, PEGDMA, Bis-EMA resin, } \\
\text { silica filler, zirconia/silica cluster filler }\end{array}$ & 82 & $4 \mathrm{~mm}$ & $\begin{array}{l}20 \mathrm{sec} \\
400-1,000 \mathrm{~mW} / \mathrm{cm}^{2} \\
10 \mathrm{sec} \\
1,000-2,000 \mathrm{~mW} / \mathrm{cm}^{2}\end{array}$ & $\begin{array}{l}\text { 3M/ESPE } \\
\text { (St Paul, MN, } \\
\text { USA) }\end{array}$ \\
\hline
\end{tabular}




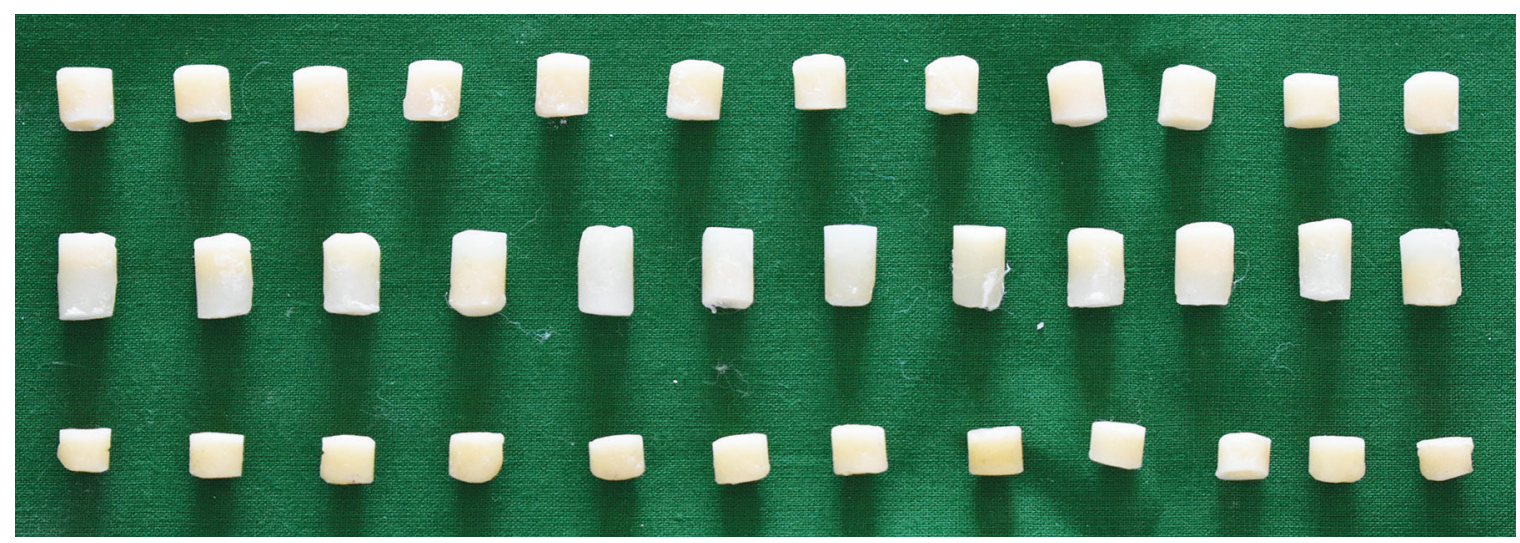

Fig. 4: Remaining part of the specimen

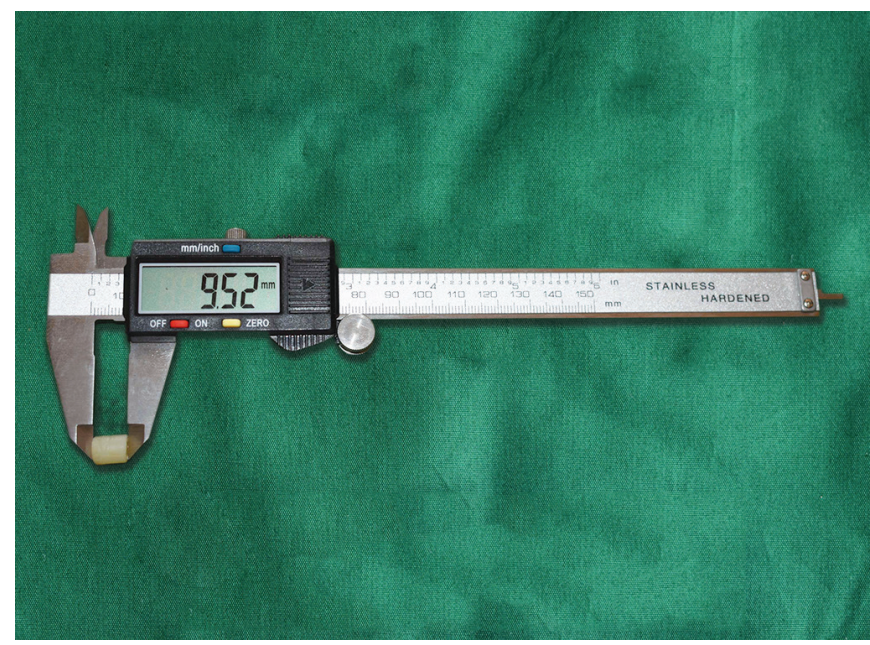

Fig. 5: Absolute length was measured using digital vernier caliper

\section{Results}

The mean depth of cure of the composite specimens was found to be higher for Group B [4.795 mm] than for Group A [3.05 mm] and Group C [2.288 mm] as shown in Table 2.

The depth of cure between the investigated materials was highly significant with $p$-value $<0.05$ (Table 3 ). The bar diagrams of depth of cure of the three composite materials are presented in Figure 6. Tukey's post hoc analysis showed a statistically significant difference between all the three groups as depicted in Table 4.

\section{Discussion}

The current study showed variation in the depth of cure between the three composites determined by the ISO 4049 method. The bulk-fill materials, namely Voco Xtra Fil and Shofu Beautifil true to their name, demonstrated higher depth of cure than the conventional composite. The conventional composite deals with incremental technique, which involves the placement, adapting, and curing of composite materials in several layers of less than 2-mm increments each due to depth of cure issues. ${ }^{7}$ In this study, Filtek Z350 XT conventional resin composite was placed in increments and its organic matrix composition includes Bis-GMA,
Table 2: Depth of cure obtained by ISO scraping test

\begin{tabular}{lcllll}
\hline Groups & $N$ & Mean & Std. deviation & Minimum & Maximum \\
\hline $\begin{array}{l}\text { Beautifil bulk-fill } \\
\text { (Group A) }\end{array}$ & 12 & 3.0583 & 0.15544 & 2.86 & 3.28 \\
$\begin{array}{l}\text { Voco Xtra Fil } \\
\text { (Group B) }\end{array}$ & 12 & 4.7958 & 0.12979 & 4.59 & 4.97 \\
$\begin{array}{l}\text { Filtek Z350 XT } \\
\text { (Group C) }\end{array}$ & 12 & 2.2883 & 0.09980 & 2.14 & 2.44 \\
Total & 36 & 3.3808 & 1.07116 & 2.14 & 4.97 \\
\hline
\end{tabular}

Table 3: Statistical analysis using one-way ANOVA

\begin{tabular}{llrlll}
\hline & Sum of squares & $d f$ & Mean square & $F$ & Sig. \\
\hline $\begin{array}{l}\text { Between } \\
\text { groups }\end{array}$ & 39.597 & 2 & 19.799 & & \\
Within groups & 0.561 & 33 & 0.017 & 1165.410 & 0.000 \\
Total & 40.158 & 35 & & & \\
\hline
\end{tabular}

Table 4: Tukey's post hoc analysis for comparison of depth of cure

\begin{tabular}{llcll}
\hline (I) Group & (J) Group & Mean difference $(I-J)$ & Std. error & Sig. \\
\hline Beautifil & Voco Xtra Fil & $-1.73750^{*}$ & 0.05321 & 0.000 \\
bulk-fill & Filtek Z350 XT & $0.77000^{*}$ & 0.05321 & 0.000 \\
Voco & Beautifil bulk-fill & $1.73750^{*}$ & 0.05321 & 0.000 \\
Xtra Fil & Filtek Z350 XT & $2.50750^{*}$ & 0.05321 & 0.000 \\
Filtek & Beautifil bulk-fill & $-0.77000^{*}$ & 0.05321 & 0.000 \\
Z350 XT & Voco Xtra Fil & $-2.50750^{*}$ & 0.05321 & 0.000 \\
\hline
\end{tabular}

* denotes that the mean difference is significant at the 0.05 level.

UDMA, TEGDMA, PEGDMA, Bis-EMA resin, silica filler, and zirconia/ silica cluster filler with $82 \%$ filler particles by weight. They are approximately $0.004-10 \mu \mathrm{m}$ in size and are based on silica and zirconia filler type. The bulk-fill composite (Voco Xtra Fil) showed a depth of cure of $4.79 \mathrm{~mm}$, whereas for conventional composite, it was $2.29 \mathrm{~mm}$, and there was a statistically significant difference. The higher depth of cure of bulk-fill composites may be due to the present modifications on their particle content, being more translucid and permitting better light penetration into deeper layers. ${ }^{8}$ Most bulk-fill composites contain camphorquinone as the 


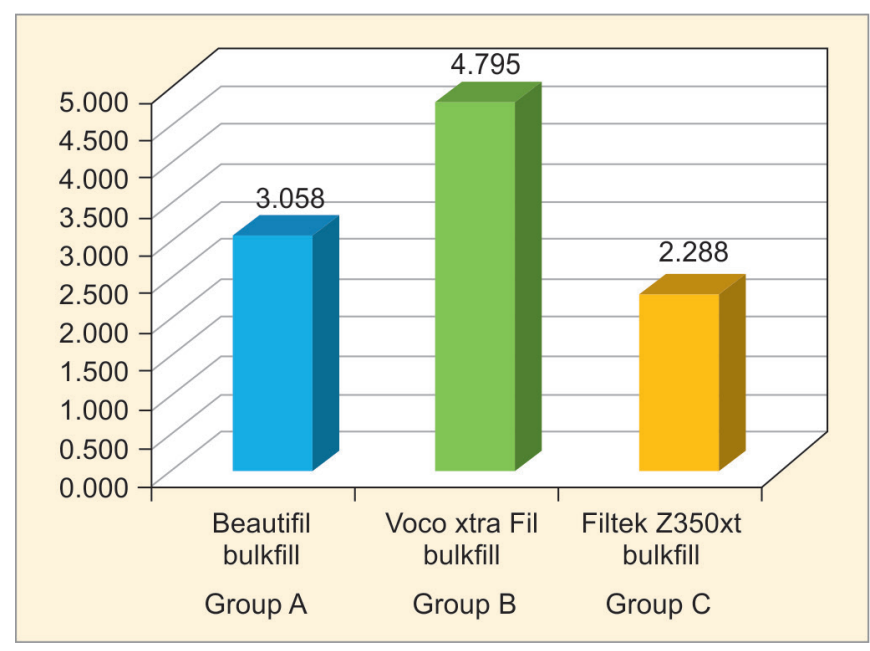

Fig. 6: Graphical representation of depth of cure

primary photoinitiator and a tertiary amine as coinitiator. ${ }^{9}$ In an in vitro study by Moharam et al., 4- to 5-mm-thick bulk-fill dental resin composites, Xtra Fil and SonicFill materials, showed adequate depth of cure. ${ }^{10}$

The bulk-fill composite (Beautifil Shofu Japan) did not achieve a $4 \mathrm{~mm}$ depth of cure. This could be due to material differences, such as shade, type of photoinitiators, and curing, which could vary with different materials. The matrix composition includes Bis-GMA, UDMA, Bis-MPEPP, TEGDMA, polymerization initiator, and pigments. They have surface pre-reacted glass-ionomer filler based on fluoroboroaluminosilicate glass particles with $87 \%$ by weight. In this study, the depth of cure of Beautifil bulk-fill composite was similar to that of results obtained by Yap et al. done using scrape test. ${ }^{11}$ However, due to varied composition, handling properties, and different physical properties, some of the bulk-fill composites failed to cure up to $4 \mathrm{~mm} .{ }^{12}$ These materials may, however, be associated with increased internal gap formation and lower physical and mechanical properties. ${ }^{13}$

Among the bulk-fill composites used, Voco Xtra Fil bulk-fill composite showed greater depth of cure than the other two composites. The Voco Xtra Fil bulk-fill composite is a newer composite based on multihybrid technology. By optimizing the filler sizes, the material achieves an extremely high filler degree of $86 \% .{ }^{14}$ The organic matrix composition consists of inorganic filler in a methacrylate matrix (Bis-GMA, UDMA, and TEGDMA) and is based on barium aluminum silicate glass.

The Bluephase 20i (Ivoclar Vivadent US) used in this study has the highest light intensity (up to $2,000 \mathrm{~mW} / \mathrm{cm}^{2}$ ) with extremely short curing times of no more than 5 seconds for light and dark composites. The wavelength of this LED curing light ranges from 385 to $515 \mathrm{~nm}$.

A number of different techniques have been employed to measure the depth of cure. These include scraping away the unset materials by using plastic spatula and measuring the remaining specimen, measuring the top and bottom hardness ratio, and measuring the top and bottom degree of conversion of double bonds in the polymer. ${ }^{15}$ In this study, scraping technique has been used as the depth of cure measure according to the ISO standard for dental resin 4049 and has been considered as a standard test. ${ }^{16}$

The parameters used in this experiment are probably conservative compared to actual clinical situations. The 1-mm distance (glass slide between resin and light tip) between the light tip and resin surface is probably the minimum, and the clinical feasibility has to be evaluated. ${ }^{17}$ This study evaluated the depth of cure of only two bulk-fill composites and compared it with a conventional composite, which is a limitation with respect to generalizing the conclusions. Besides these, we have to conduct in vivo studies too to identify the relationship between depth of cure of bulk-fill resin-based composites and its associated factors including degree of conversion and cytotoxicity.

\section{ConCLUSION}

Within the limitations of the study, it can be concluded that the placement of bulk-fill composites with 3-mm increments is mandatory for complete curing.

\section{References}

1. van de Sande FH, Moraes RR, Elias RV, et al. Is composite repair suitable for anterior restorations? A long-term practice-based clinical study. Clin Oral Investig 2019;23(6):2795-2803. DOI: 10.1007/s00784-0182722-5.

2. Ibarra ET, Lien W, Casey J, et al. Physical properties of a new sonically placed composite resin restorative material. Gen Dent 2015;63(3): $51-56$.

3. Calheiros FC, Pfeifer CS, Brandão LL, et al. Flexural properties of resin composites: Influence of specimen dimensions and storage conditions. Dent Mater J 2013;32(2):228-232. DOI: 10.4012/dmj. 2012-271.

4. Anusavice KJ. In: Anusavice KJ, editor. Phillip's science of dental materials, 11th ed. St. Louis: Saunders Co; 2003. p. 655-719.

5. Ilie N, Bucuta S, Draenert M. Bulk-fill resin-based composites: an in vitro assessment of their mechanical performance. Oper Dent 2013;38(6):618-625. DOI: 10.2341/12-395-L.

6. Guney T, Yazici AR. 24-Month clinical evaluation of different bulkfill restorative resins in class II restorations. Oper Dent 2020;45(2): 123-133. DOI: 10.2341/18-144-C.

7. Kaisarly D, El Gezawi M, Keßler A, et al. Shrinkage vectors in flowable bulk-fill and conventional composites: bulk versus incremental application. Clin Oral Investig 2020:1-3. DOI: 10.1007/s00784-02003412-3.

8. Rauber GB, Bernardon JK, Vieira LC, et al. In vitro fatigue resistance of teeth restored with bulk fill versus conventional composite resin. Braz Dent J 27(4):452-457. DOI: 10.1590/0103-6440201600836.

9. Van Ende A, De Munck J, Lise DP, et al. Bulk-fill composites: a review of the current literature. J Adhes Dent 2017;19(2):95-109. DOI: 10.3290/j. jad.a38141.

10. Moharam LM, El-Hoshy AZ, Abou-Elenein K. The effect of different insertion techniques on the depth of cure and vickers surface microhardness of two bulk-fill resin composite materials. J Clin Exp Dent 2017;9(2):e266-e271. DOI: 10.4317/jced.53356.

11. Yap AU, Pandya M, Toh WS. Depth of cure of contemporary bulk-fill resin-based composites. Dent Mater J 2016;31;35(3):503-510. DOI: 10.4012/dmj.2015-402.

12. Benetti AR, Havndrup-Pedersen $C$, Honoré $D$, et al. Bulk-fill resin composites: polymerization contraction, depth of cure, and gap formation. Oper Dent 2015;40(2):190-200. DOI: 10.2341/13-324-L.

13. Aravamudhan K, Rakowski D, Fan PL. Variation of depth of cure and intensity with distance using LED curing lights. Dent Mater 2006;22(11):988-994. Epub 2006. DOI: 10.1016/j.dental.2005. 11.031.

14. Rizzante FA, Duque JA, Duarte MA, et al. Polymerization shrinkage, microhardness and depth of cure of bulk fill resin composites. Dent Mater J 2019;38(3):403-410. DOI: 10.4012/dmj.2018-063.

15. Moore BK, Platt JA, Borges G, et al. Depth of cure of dental resin composites: ISO 4049 depth and microhardness of types of materials and shades. Oper Dent 2008;33(4):408-412. DOI: 10.2341/07-104. 
16. de Cássia Romano B, Soto-Montero J, Rueggeberg FA, et al. Effects of extending duration of exposure to curing light and different measurement methods on depth-of-cure analyses of conventional and bulk-fill composites. Eur J Oral Sci 2020;128(4):336-344. DOI: 10.1111/eos.12703.
17. Lindberg A, Peutzfeldt A, van Dijken JW. Effect of power density of curing unit, exposure duration, and light guide distance on composite depth of cure. Clin Oral Investig 2005;9(2):71-76. DOI: 10.1007/s00784005-0312-9. 